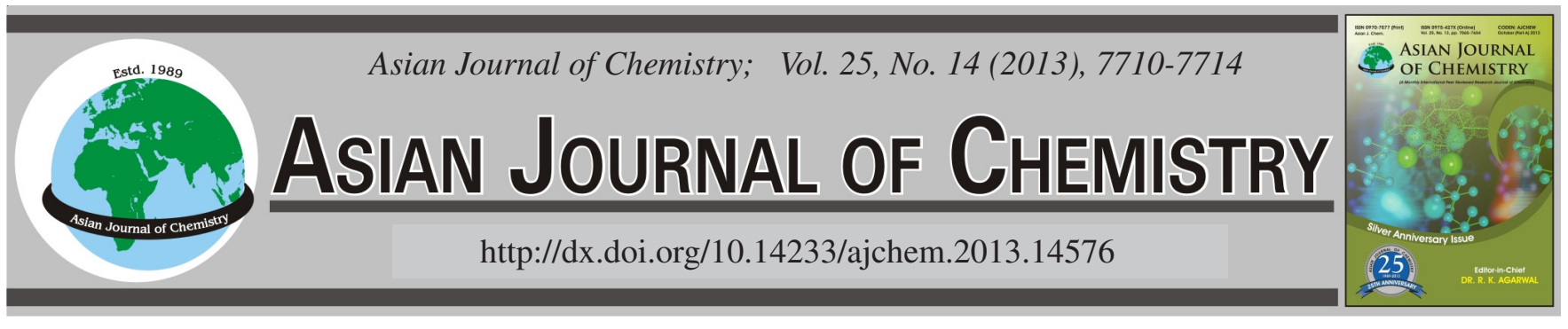

\title{
Use of Opuntia dillenii Seeds for Sorptive Removal of Acidic Textile Dyes from Water in Benign Way
}

Farah Kanwal ${ }^{1}$, Rabia Rehman ${ }^{1, *}$, Muhammad Waheed Mushtaq $^{1}$, Aisha Batool $^{2}$ and Shahzad Naseem ${ }^{2}$

${ }^{1}$ Institute of Chemistry, University of the Punjab, New Campus, Lahore-54590, Pakistan

${ }^{2}$ Centre of Excellence in Solid State Physics, University of the Punjab, New Campus, Lahore-54590, Pakistan.

*Corresponding author: Fax: +92 42 99230998; Tel: +92 42 99230463; Ext: 870; E-mail: grinorganic@ yahoo.com

(Received: 14 September 2012;

Accepted: 8 July 2013)

AJC-13791

In this study, the use of Opuntia dillenii seeds (O.D.S) has been investigated as an adsorbent for removing two textile dyes i.e., drimarene blue $\mathrm{K}_{2} \mathrm{RL}$ and eosin $\mathrm{B}$, from aqueous medium. Adsorption related factors, like adsorbent dose, contact time, $\mathrm{pH}$ of dye solution and temperature were optimized in batch mode by adopting one variable methodology for optimizing conditions. Then isothermal, thermodynamical and kinetic studies were carried out at optimized conditions of adsorption and it is found that maximum adsorption capacity of Opuntia dillenii seeds for removing drimarene blue $\mathrm{K}_{2} \mathrm{RL}$ and eosin B were 100 and $7.96 \mathrm{mg} \mathrm{g}^{-1}$, respectively, following pseudo-second order kinetic model. Ethanol and $\mathrm{NaOH}$ were found suitable for regenerating used Opuntia dillenii seeds as compared to $\mathrm{HCl}$ or water. So, Opuntia dillenii seeds can be effectively employed for waste water treatment in economical way, using indigenous sources.

Key Words: Opuntia dillenii seeds, Eosin B, Drimarene blue $\mathrm{K}_{2} \mathrm{RL}$, Adsorption.

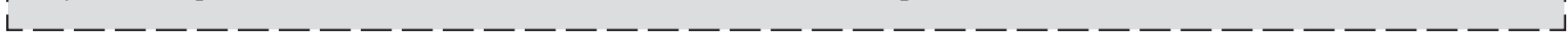

\section{INTRODUCTION}

Wastewater treatment by adsorption is gaining importance now-a-days. Researchers all over the world are trying to explore new adsorbents for replacing activated charcoal from their indigenous sources. These adsorbents are mostly originated from agrowaste, like peels of banana, orange or pea; corncobs or barley husks, rice husk, wheat husks, plant leaves, seeds of melon or guava, etc. or industrial waste like municipal waste sludge, deoiled soya ${ }^{1-12}$. Main advantage of using them is low cost of raw materials. Others are: recycling of waste, less import cost due to the use of simple machinery and indigenous adsorbents and last but not the least, it is environmental friendly process. Other water treatment methodologies, like chemical precipitation, photochemical oxidation, ozonation or microbial degradation processes are not environmental friendly, nor very cost effective. Expensive machinery and specialists are required for them ${ }^{13-16}$.

Wastewater containing synthetic dyes is difficult to treat because of stability of dye molecules and other by products produced either by their excess reactivity, like metal complexes or by photochemical degradation processes. In textile industry, mostly synthetic dyes are employed. They belong to various classes, like cationic, anionic, neutral, anthraquinone, metal complexes, etc. In following study, drimarene blue $\mathrm{K}_{2} \mathrm{RL}$ (D.R) and Eosin B (E.B) have been investigated. Drimarene blue $\mathrm{K}_{2} \mathrm{RL}$ is an example of anthraquinone dye (Fig. 1), which<smiles>[NH3+]c1ccc(Nc2nc(Cl)nc(F)c2Cl)c2c1C(=O)C1C=CC=CC1C2=O</smiles>

Fig. 1. Drimarene blue $\mathrm{K}_{2} \mathrm{RL}$ dye

represents the second largest class of textile dyes (reactive dyes) and are used extensively due to their wide array of colour shades, ease of application and minimal energy consumption. They are resistant to biodegradation due to their complex aromatic structure ${ }^{17}$. Eosin $\mathrm{B}\left(\mathrm{C}_{20} \mathrm{H}_{6} \mathrm{Br}_{2} \mathrm{~N}_{2} \mathrm{Na}_{2} \mathrm{O}_{9}\right)$ is a dibromo dinitro derivate of fluorescein (dibromodinitrofluorescein sodium, Fig. 2) having molecular formula with molecular weight 624.06 amu. Its systematic name is disodium 2-(4,5-dibromo2,7-dinitro-6-oxido-3-oxo-3H-xanthen-9-yl) benzoate. It is widely used as a biological staining to estimate a wide range of proteins because in acidic solution, it binds to proteins. It is harmful in case of swallowing, inhaling or skin contact resulting in gastrointestinal tract infection and skin rashes ${ }^{18}$. 
<smiles>O=C([O-])c1ccccc1-c1c2cc([N+](=O)[O-])c(=O)c(Br)c-2oc2c(Br)c([N+](=O)[O-])c([N+](=O)[O-])cc12</smiles>

Fig. 2. Eosin B dye

In this case, finally crushed seeds of Opuntia dillenii are used for adsorption studies. Its other botanical name is Cactus indicus Roxb. and local names are Vidhara, Vishwa, Saraka, Nagphani. It belongs to Cactaceae family of plant. It is a succulent, perennial, xerophytic shrub, growing up to $1 \mathrm{~m}$ high. They grow from rounded cushion like tubercles, having yellow flower and purple fruit with curved thrones. Fruits fleshy contain compressed stony hard seeds. Its various parts are used in ayurvedic medicines for treatment of burning sensations, asthma, whooping cough, hepatitis, poison, fever, constipation, conjunctivitis, boils, ulcers, edema and leucorrhea etc. The chemical characteristics of Opuntia dillenii seeds are given in Table- $1^{19,20}$.

TABLE-1

\begin{tabular}{lc}
\multicolumn{2}{c}{ TABLE-1 } \\
CHARACTERIZATION OF Opuntia dillenii SEEDS \\
\hline \multicolumn{1}{c}{ Parameters } & Contents values \\
\hline Moisture (\%) & 81.68 \\
Fibre $(\%)$ & 9.49 \\
Ash $(\%)$ & 0.437 \\
$\mathrm{pH}$ & 3.34 \\
Acidity $(\mathrm{g} / 100 \mathrm{~g})$ & 1.23 \\
Phenolics $(\mathrm{mg} / 100 \mathrm{~g})$ & 117 \\
\hline
\end{tabular}

\section{EXPERIMENTAL}

Preparation of adsorbent: The adsorbent, Opuntia dillenii seeds (O.D.S.) were collected from Quaid-e-Azam campus of Punjab University Lahore. They were washed and dried in sunlight for 5 days and then in an oven at $80{ }^{\circ} \mathrm{C}$. Dry biomass was crushed into granules, sieved through 50 mesh and preserved in sample bottles for use.

Preparation of adsorbate: Drimarene blue $\mathrm{K}_{2} \mathrm{RL}$ (Clariant Sandoz, C.I: Reactive blue 209) and eosin B $\left(\mathrm{C}_{20} \mathrm{H}_{6} \mathrm{Br}_{2} \mathrm{~N}_{2} \mathrm{Na}_{2} \mathrm{O}_{9}\right.$, acid red-91, C.I: 45400, MW 624.1, xanthene dye example) were obtained from Clariant Pakistan limited and used without any further purification. Stock solution of $1000 \mathrm{ppm}$ concentration of these dyes were prepared using $0.1 \mathrm{~g}$ dye powder $/ 100 \mathrm{~mL}$ double distilled water. Further standards and working solutions were prepared by diluting respective dye stock solution.

Batch adsorption experiments: Adsorption experiments were performed by taking $50 \mathrm{~mL}$ dye solution of dye $(50 \mathrm{mg}$ $\left.\mathrm{L}^{-1}\right)$ and treated with $0.1 \mathrm{~g}$ of adsorbent dose. The variables studied were: solution $\mathrm{pH}(2-10)$, temperature $\left(20-70{ }^{\circ} \mathrm{C}\right)$, adsorbent dose (0.1-1.0 g) and contact interval between dye and Opuntia dillenii seeds (10-60 min). After adsorption, samples were centrifuged to remove Opuntia dillenii seeds and progress of adsorption was determined spectrophotometrically by setting $\lambda_{\max }$ at 620 and $530 \mathrm{~nm}$ for drimarene blue $\mathrm{K}_{2} \mathrm{RL}$ and eosin $\mathrm{B}$, respectively. Optimized conditions of all variables were further employed for isothermal, thermodynamical and kinetic studies. The percentage adsorption of dyes on Opuntia dillenii seeds were quantified by eqn. 1 .

$$
\text { Adsorption }(\%)=\left[\frac{\left(\mathrm{C}_{\mathrm{o}}-\mathrm{C}_{\mathrm{e}}\right)}{\mathrm{C}_{\mathrm{o}}}\right] \times 100
$$

In eqn. $1, \mathrm{C}_{\mathrm{o}}$ is dye concentration before adsorption and $\mathrm{C}_{\mathrm{e}}$ representing concentration in $\mathrm{mg} \mathrm{L}^{-1}$. Experiments were performed in duplicate order and average values were used for graphical spinel representation of optimization of adsorption factor and line-to-line trend model is adopted for graphical representation of isothermal and kinetic modeling of equilibrium data $^{21-24}$. For regenerating used Opuntia dillenii seeds, its 5.0 $\mathrm{g}$ was dipped separately in $100 \mathrm{~mL}$ of distilled water, ethanol, $0.01 \mathrm{M} \mathrm{HCl}$ and $0.01 \mathrm{M} \mathrm{NaOH}$ solutions for $0.5 \mathrm{~h}$, while shaking at $100 \mathrm{rpm}$ on orbital shaker. Then percentage desorption of dyes from Opuntia dillenii seeds were quantified by eqn. 2 .

$$
\text { Desorption }(\%)=\frac{q_{\text {des }}}{q} \times 100
$$

where $\mathrm{q}$ and $\mathrm{q}_{\mathrm{des}}$ are $\mathrm{mg} \mathrm{g}^{-1}$ of dye adsorbed and desorbed, respectively ${ }^{25}$.

\section{RESULTS AND DISCUSSION}

Optimization of adsorption parameters of dye: The optimization of adsorption parameters of drimarene blue $\mathrm{K}_{2} \mathrm{RL}$ and eosin B dyes were carried out separately on Opuntia dillenii seeds in batch mode and their results are given in Figs. 3-6 in comparative mode.

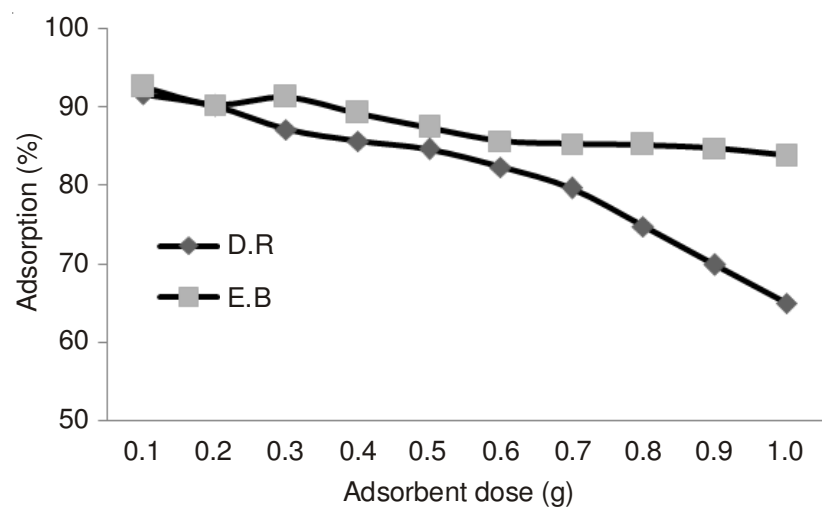

Fig. 3. Effect of adsorbent dose on percentage removal of dyes using Opuntia dillenii seeds. Where D.R = drimarene blue $\mathrm{K}_{2} \mathrm{RL}$ dye and E.B $=$ eosin B dye

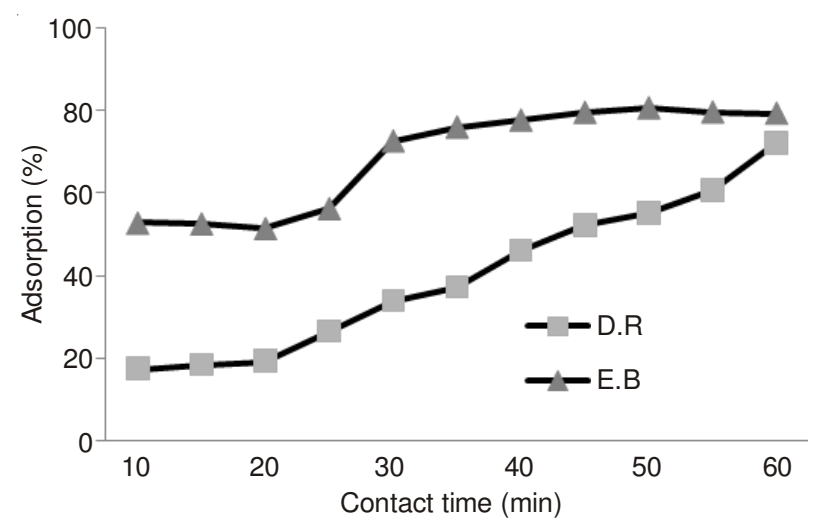

Fig. 4. Effect of contact time percentage removal of dyes using Opuntia dillenii seeds. Where D.R = drimarene blue $\mathrm{K}_{2} \mathrm{RL}$ dye and E.B = eosin B dye 


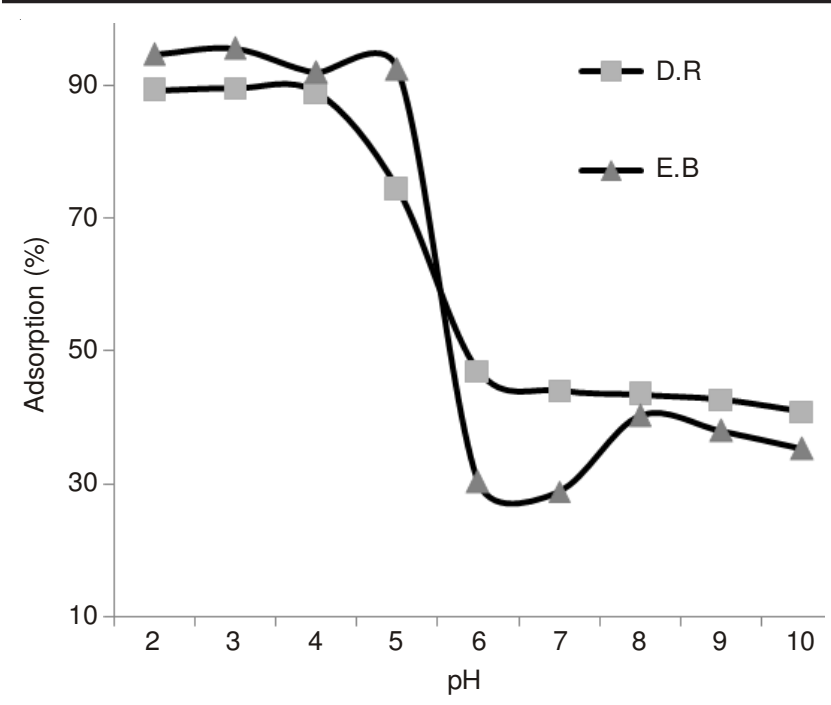

Fig. 5. Effect of $\mathrm{pH}$ on percentage removal of dyes using Opuntia dillenii seeds. Where D.R = drimarene blue $\mathrm{K}_{2} \mathrm{RL}$ dye and $\mathrm{E} \cdot \mathrm{B}=\operatorname{eosin} \mathrm{B}$ dye

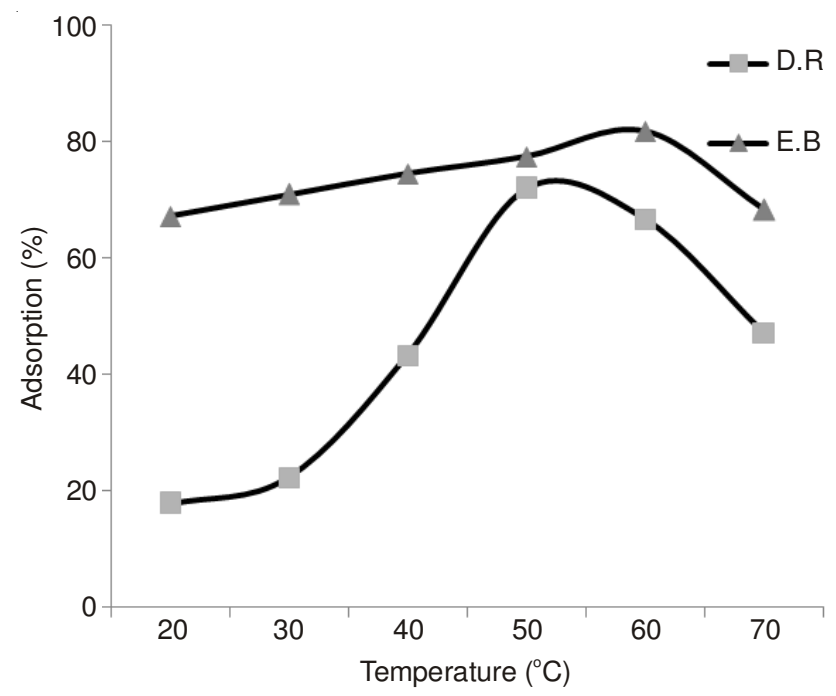

Fig. 6. Effect of temperature on percentage removal of dyes using Opuntia dillenii seeds. Where D.R = drimarene blue $\mathrm{K}_{2} \mathrm{RL}$ dye and E.B = eosin B dye

Fig. 3 shows the effect of adsorbent dose on percentage removal of dyes using Opuntia dillenii seeds. It can be seen from this figure that maximum adsorption of drimarene blue $\mathrm{K}_{2} \mathrm{RL}$ occurred when adsorbent dose was $0.3 \mathrm{~g}$, while for eosin $\mathrm{B}$, it was $0.1 \mathrm{~g}$. Requirement of small quantities of Opuntia dillenii seeds for maximum removal of dyes indicated that it has good adsorption tendency due to its mucilaginous, acidic, phenolic and fibrous nature, which was found during its characterization by Medina et ll $^{20}$. Further increase in adsorbent dose showed negative impact on adsorption due to agglomeration of Opuntia dillenii seeds particles in solution, which reduces exposed surface area of Opuntia dillenii seeds

Fig. 4 is representing the effect of contact time on percentage removal of dyes using Opuntia dillenii seeds. In both case, maximum removal of dyes occurred at $1 \mathrm{~h}$ interval. There is a rapid increase in adsorption rate at the beginning following in gradual consistency till equilibrium. At initial stages, more vacant adsorption sites were available at the surface of Opuntia dillenii seeds, but after 30-40 min, adsorption rates become slower due to the penetration of larger dye, molecules in inner binding sites of Opuntia dillenii seeds, which were not directly exposed to dye solution.

The $\mathrm{pH}$ effect of dye solution on adsorption is shown in Fig. 5. It clearly shows that drimarene blue $\mathrm{K}_{2} \mathrm{RL}$ and eosin $\mathrm{B}$ adsorbed more in acidic conditions and adsorption decreased to very low level in basic conditions. Maximum adsorption of drimarene blue $\mathrm{K}_{2} \mathrm{RL}$ and eosin B on Opuntia dillenii seeds occurred at $\mathrm{pH} 4$ and 5, respectively. In acidic conditions dye species exit in ionic form which can interact more with chelating sites of adsorbent. Acidic conditions also help in hydrolysis of ligno-cellulosic material of Opuntia dillenii seeds, which results in exposure of more binding sites for chemisorptive removal of dye $\mathrm{e}^{26}$.

Effect of temperature on adsorption of drimarene blue $\mathrm{K}_{2} \mathrm{RL}$ and eosin B dyes by Opuntia dillenii seeds is shown in Fig. 6. It shows that maximum adsorption of drimarene blue $\mathrm{K}_{2} \mathrm{RL}$ and eosin B on Opuntia dillenii seeds occurred at 50 and $60{ }^{\circ} \mathrm{C}$, respectively. At higher temperature, Opuntia dillenii seeds cellulosic components are swelled up, exposing more porous sites which help in physiosorptive removal of dye molecules in efficient way. At relatively high temperature, thermal degradation of dye molecules results in smaller fragments, which can be adsorbed better as compared to bigger one. But at high temperature, adsorption is retarded because it is an exothermic process naturally ${ }^{25,27}$.

Kinetic modeling of adsorption: Pseudo-second order kinetic model is usually followed in adsorption of dye molecules by agrowaste materials ${ }^{12-22}$. Linear form of Ho and McKay pseudo-second order kinetic model is given in eqn. $3^{28}$.

$$
\frac{\mathrm{t}}{\mathrm{q}}=\frac{1}{\mathrm{k}_{2} \mathrm{q}_{\mathrm{e}}}+\frac{1}{\mathrm{q}_{\mathrm{e}} \mathrm{t}}
$$

where $\mathrm{q}_{\mathrm{e}}$ and $\mathrm{q}_{\mathrm{t}}$ are the adsorption capacity at equilibrium and at time $\mathrm{t}$, respectively $\left(\mathrm{mg} \mathrm{g}^{-1}\right)$ and $\mathrm{k}$ is the rate constant of pseudo-second order sorption $\left(\mathrm{g} \mathrm{mg}^{-1} \mathrm{~min}^{-1}\right)$. A line-to-line trend showing plot is drawn using $1 / \mathrm{t}$ at $\mathrm{x}$-axis and t/q at $\mathrm{y}$-axis and presented in Fig. 7. Correlation coefficient ${ }^{2}{ }^{21}$ values are 0.765 and 0.844 for adsorption of drimarene blue $\mathrm{K}_{2} \mathrm{RL}$ and eosin B dyes by Opuntia dillenii seeds adsorbent, indicating that this model is applicable on this adsorption system. It means chemisorptive removal of dyes occurred involving intra-particle diffusion and mass transfer mechanisms ${ }^{28}$.

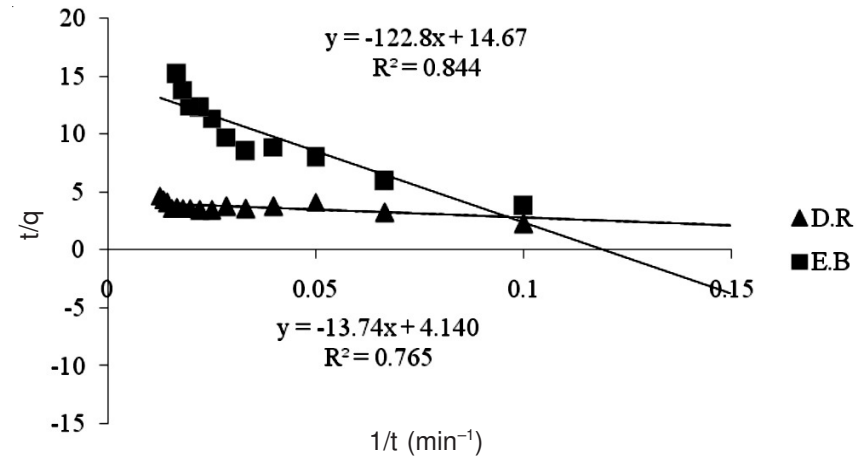

Fig. 7. Psudo-second order modeling of equilibrium data for adsorption of dyes by Opuntia dillenii seeds. Where D.R = drimarene blue $\mathrm{K}_{2} \mathrm{RL}$ dye and E. $\mathrm{B}=\operatorname{eosin} \mathrm{B}$ dye 
Isothermal and thermodynamical modeling of adsorption: These modeling of equilibrium data are carried out by applying the optimized conditions simultaneously at higher dye concentration solutions and results are graphically represented in Figs. 8 and 9 and related parameters are given in Table-2.

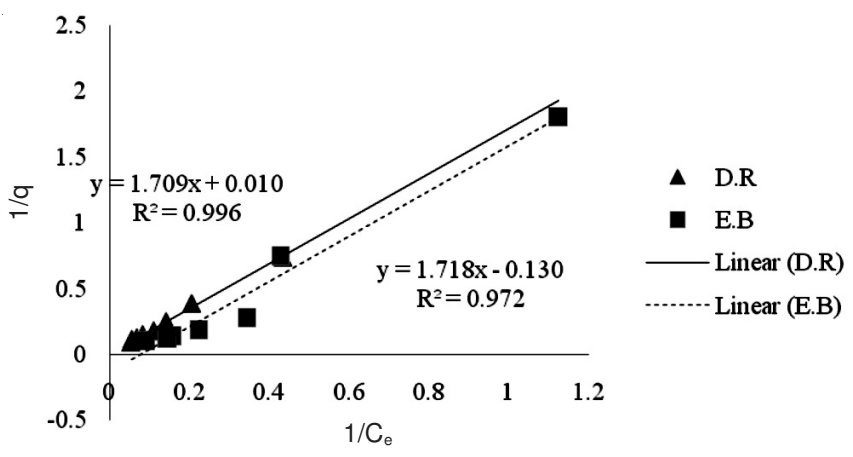

Fig. 8. Langmuir isotherms for dyes using Opuntia dillenii seeds as adsorbent. Where D.R = drimarene blue $\mathrm{K}_{2} \mathrm{RL}$ dye and E. $\mathrm{B}=$ eosin B dye

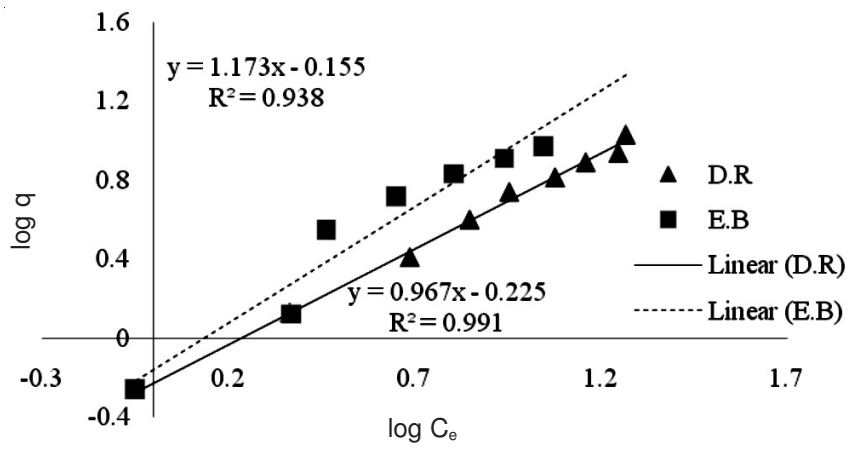

Fig. 9. Freundlich isotherms for dyes using Opuntia dillenii seeds as adsorbent. Where D.R = drimarene blue $\mathrm{K}_{2} \mathrm{RL}$ dye and E.B = eosin B dye

Langmuir isotherm: Its linearized form is given in eqn. $4^{25}$ :

$$
\frac{1}{\mathrm{q}}=\frac{1}{\mathrm{bq}_{\mathrm{m}} \mathrm{C}_{\mathrm{e}}}+\frac{1}{\mathrm{q}_{\mathrm{m}}}
$$

Here ' $b$ ' $\left(\mathrm{L} \mathrm{g}^{-1}\right)$ is empirical constant, indicating the affinity of Opuntia dillenii seeds towards dyes, used further for thermodynamic calculations and ' $\mathrm{q}_{\max }$ ' is maximum adsorption capacity of Opuntia dillenii seeds $\left(\mathrm{mg} \mathrm{g}^{-1}\right)$. Their values are determined from regression analysis of graph showing in Fig. 8. Maximum adsorption capacity of Opuntia dillenii seeds for removing drimarene blue $\mathrm{K}_{2} \mathrm{RL}$ is $100 \mathrm{mg} \mathrm{g}^{-1}$, while for removing eosin $\mathrm{B}$, it is $7.69 \mathrm{mg} \mathrm{g}^{-1}$. The parameter ' $\mathrm{b}$ ' is used to calculate separation factor ' $\mathrm{R}_{\mathrm{L}}$ ' using eqn. $5^{25}$ :

$$
\mathrm{R}_{\mathrm{L}}=\frac{1}{1+\mathrm{bC}_{\mathrm{o}}}
$$

' $R_{L}$ ' values between 0-1 depicts favourable adsorption. In this case, ' $\mathrm{R}_{\mathrm{L}}$ ' for drimarene blue $\mathrm{K}_{2} \mathrm{RL}$ is 0.00034 and for eosin $\mathrm{B}$, it is 0.208 . It clearly favours the feasibility of this process. Further ' $b$ ' is used to determine Gibbs free energy change $\left(\Delta \mathrm{G}^{\circ}\right)$ using eqn. $6^{25}$ :

$$
\Delta \mathrm{G}^{\mathrm{o}}=-\mathrm{RT} \ln (\mathrm{K})
$$

where $\Delta \mathrm{G}^{\mathrm{o}}$ in $\mathrm{KJ} / \mathrm{mol}$, ' $\mathrm{T}$ ' is room temperature in Kelvin, ' $\mathrm{R}$ ' is the universal gas and ' $\mathrm{K}$ ' is the reciprocal of Langmuir constant ' $b$ '. Negative values indicate the spontaneity of this process.

Freundlich isotherm: The equilibrium data obtained with varying concentration of dye and fixed dose of adsorbent was applied to the Freundlich isotherm (eqn. 7$)^{25}$ :

$$
\log \mathrm{q}=\log \mathrm{K}_{\mathrm{F}}+\frac{1}{\mathrm{n}} \log \mathrm{C}_{\mathrm{e}}
$$

' $\mathrm{K}_{\mathrm{F}}$ ' and ' $\mathrm{n}$ ' are Freundlich constants, calculated by slope and intercept of the graph between ' $\log \mathrm{C}_{\mathrm{e}}$ ' and 'log q'.

The values of $\mathrm{n}$ are lie between 0 and 1 (Table-2), indicated that physiosorptive removal of dyes occurred efficiently.

On the whole, Langmuir model is more applicable to equilibrium data as compared to Freundlich model, as clear from their respective correlation coefficient values, which are greater in case of Langmuir model. It means that chemisorptive removal of dye molecules occurred more on homogenously distributed binding sites on Opuntia dillenii seeds in monolayer fashion as compared to physiosorption on heterogeneous binding sites in multilayer fashion.

Regeneration of adsorbent: The used Opuntia dillenii seeds was regenerated by using double distilled water, ethanol, $\mathrm{NaOH}$ and $\mathrm{HCl}$ and results shown in Fig. 10. It is clear from this graph that ethanol is more efficient in desorbing dye from Opuntia dillenii seeds as compared to other desorbents used. The relative order is as followed: ethanol $>$ water $>\mathrm{NaOH}>$ $\mathrm{HCl}$. Dyes are more soluble in ethanol as compared to water due to their aromatic nature, that's why desorb more with it. While using acid or base for desorption, base is more efficient

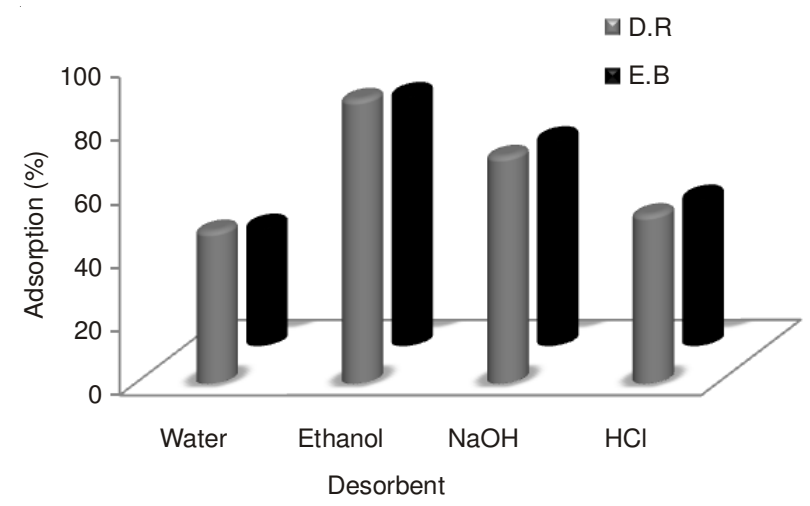

Fig. 10. Regeneration of Opuntia dillenii seeds using different eluents

\begin{tabular}{|c|c|c|c|c|c|c|c|c|}
\hline \multirow{2}{*}{ Dyes } & \multicolumn{4}{|c|}{ Langmuir isotherm parameters } & \multicolumn{3}{|c|}{ Freundlich isotherm parameters } & \multirow{2}{*}{$\begin{array}{c}\text { Thermodynamic parameters } \\
\Delta \mathrm{G}^{\mathrm{o}}(\mathrm{KJ} / \mathrm{mol})\end{array}$} \\
\hline & $\mathrm{R}^{2}$ & $\mathrm{q}_{\mathrm{m}}\left(\mathrm{mg} \mathrm{g}^{-1}\right)$ & $\mathrm{b}\left(\mathrm{L} \mathrm{g}^{-1}\right)$ & $\mathrm{R}_{\mathrm{L}}$ & $\mathrm{R}^{2}$ & $\mathrm{~K}_{\mathrm{F}}$ & $\mathrm{n}$ & \\
\hline Drimarene blue $\mathrm{K}_{2} \mathrm{RL}$ & 0.996 & 100 & 58.51 & 0.00034 & 0.991 & 0.595 & 0.852 & 10.08 \\
\hline Eosin B & 0.972 & 7.69 & 0.076 & 0.208 & 0.938 & 0.699 & 1.034 & -6.38 \\
\hline
\end{tabular}
Where D.R = drimarene blue $\mathrm{K}_{2} \mathrm{RL}$ dye and E. B = eosin B dye

TABLE-2

ISOTHERMAL AND THERMODYNAMICAL PARAMETERS FOR BIOSORPTION OF DYES ON Opuntia dillenii SEEDS 
in this case, because these dyes are acidic in nature, so more easily neutralized by base and desorbed from adsorbent.

\section{Conclusion}

So, it is obvious from results that Opuntia dillenii seeds can be efficiently employed for removing acidic synthetic dyes, namely: drimarene blue $\mathrm{K}_{2} \mathrm{RL}$ and eosin $\mathrm{B}$, from aqueous medium. Optimized conditions for removal of drimarene blue $\mathrm{K}_{2} \mathrm{RL}$ by Opuntia dillenii seeds are: $\mathrm{pH}=4$, contact time $=1 \mathrm{~h}$, temperature $=50{ }^{\circ} \mathrm{C}$, adsorbent dose $=0.1 \mathrm{~g}$ and for eosin $\mathrm{B}$ their values are: $\mathrm{pH}=5$, contact time $=1 \mathrm{~h}$, temperature $=60^{\circ} \mathrm{C}$, adsorbent dose $=0.3 \mathrm{~g}$ following dominantly chemisorptive pseudo-second order kinetics with maximum removing efficiency of 100 and $7.69 \mathrm{mg} \mathrm{g}^{-1}$, respectively. The used Opuntia dillenii seeds can be recycled by desorbing with ethanol. So, Opuntia dillenii seeds can be used for dyes removal from water on larger scale.

\section{REFERENCES}

1. J. Liu, H. Luo and C. Wei, T. Nonferr. Met. Soc., 17, 880 (2007).

2. G. Moussavi and M. Mahmoudi, J. Hazard. Mater., 168, 806 (2009).

3. M.M. El Zawahry and M.M. Kamel, Water Res., 38, 2967 (2004).

4. M.M. Dávila-Jiménez, M.P. Elizalde-González and V. HernándezMontoya, Bioresour. Technol., 100, 6199 (2009).

5. M.P. Elizalde-González and V. Hernández-Montoya, Bioresour. Technol., 100, 2111 (2009).

6. M.A.M. Salleh, D.K. Mahmoud, W.A.W.A. Karim and A. Idris, Desalination, 280, 1 (2011).
7. G.M. Walker and L.R. Weatherley, Environ. Pollut., 108, 219 (2000).

8. P.-S. Ong, S.-T. Ong and Y.-T. Hung, Asian J. Chem., 25, 6141 (2013).

9. S.W. Won, M.H. Han and Y.S. Yun, Water Res., 42, 4847 (2008).

10. Z. Aksu, Process Biochem., 40, 997 (2005).

11. S.T. Akar, A. Gorgulu, T. Akar and S. Celik, Chem. Eng. J., 168, 125 (2011)

12. N. Iqbal, M. Imran, J. Iqbal and Z. Mahmood, Asian J. Chem., 22, 1993 (2010).

13. O. Aksakal and H. Ucun, J. Hazard. Mater., 181, 666 (2010).

14. K.V. Radha, I. Regupathi, A. Arunagiri and T. Murugesan, Process Biochem., 40, 3337 (2005).

15. F. Ferrero, J. Hazard. Mater., 142, 144 (2007).

16. Y. Kismir and A.Z. Aroguz, Chem. Eng. J., 172, 199 (2011).

17. M.F. Siddiqui, S. Andleeb, N. Ali, P.B. Ghumro and S. Ahmed, Afri. J. Biotechnol., 8, 5570 (2009).

18. Y. Qu, S. Shi, F. Ma and B. Yan, Bioresour. Technol., 101, 8016 (2010).

19. H. Bohm, J. Prof. Assoc. Cactus Dev., 10, 148 (2008).

20. E.M.D. Medina, E.M.R. Rodriguez and C. Diaz Romero, Food Chem., 103, 38 (2007).

21. S. Zhou and A.K. Ray, Ind. Eng. Chem. Res., 42, 6020 (2003).

22. V.S. Mane and P.V.V. Babu, Desalination, 273, 321 (2011).

23. A. Demirbas, J. Hazard. Mater., 167, 1 (2009).

24. S.B. Bukallah, M.A. Rauf and S.S. Al-Ali, Dyes Pigm., 74, 85 (2007).

25. R. Rehman, J. Anwar and T. Mahmud, J. Chem. Soc. Pak., 34, 460 (2012).

26. M.T. Uddin, M. Rukanuzzaman, M.M.R. Khan and M.A. Islam, J. Environ. Manage., 90, 3443 (2009).

27. R. Gong, X. Zhang, H. Liu, Y. Sun and B. Liu, Bioresour. Technol., 98, 1319 (2007).

28. Y.S. Ho and G. McKay, Trans. IChemE, 76B, 332 (1998). 